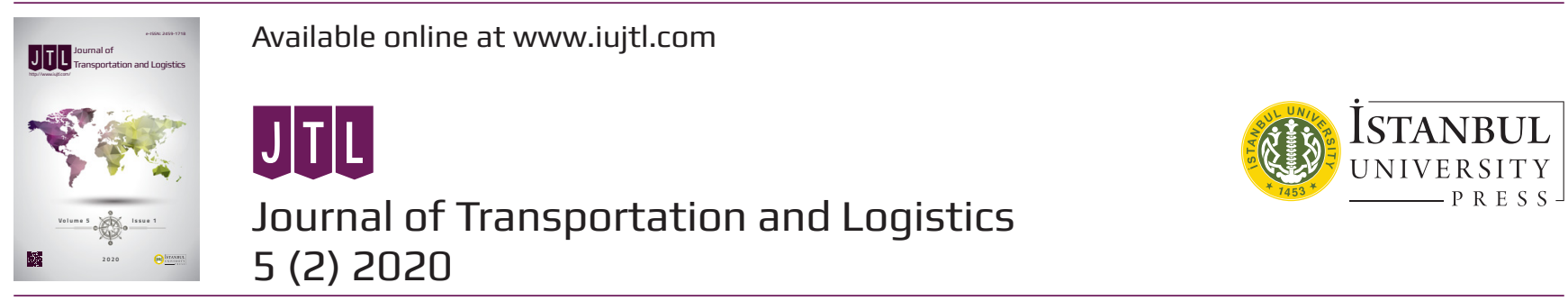

\title{
Measuring Digital Divide in E-Commerce by Log-Linear Models and Non-Parametric Tests: An Application of Turkey
}

\author{
Sultan Kuzu Yıldııım 10 , Çiğdem Arıcıgil Çilan² (1)
}

\section{ABSTRACT}

The purpose of the study is to examine the relationships between individuals who engage in e-commerce and their demographic factors and to investigate whether their status of e-commerce engagement differentiates according to demographic factors. In case of differences, demographic factors caused by the Digital Divide were examined. If Digital Division is not detected, the reasons for this are emphasized. For this purpose, the overall profile of the customer group engaged in e-commerce in Turkey was summarized, and the demographic variables that e-commerce is associated with were determined using Non-Parametric techniques. Then, utilizing the Log-Linear Models, one of the methods of the Advanced Contingency Table Analysis, the effects including two-way and three-way interactions were investigated. Consequently, among those who engage in e-commerce in Turkey, it was determined that education caused the digital divide, however, gender remained ineffective.

Keywords: Digital Divide, E-Commerce, Contingency Table, Non-Parametric Tests, Log-Linear Models

1 Corresponding author: Sultan Kuzu Yıldırım / Istanbul University, Faculty of Business, İstanbul, Turkey E-mail: sultan.kuzu@istanbul.edu.tr, ORCID: 0000-0001-6577-1584

2 Çiğdem Arıcıgil Çilan / Istanbul University, Faculty of Business, İstanbul, Turkey, E-mail: ccilan@istanbul.edu.tr, ORCID: 0000-0002-7862-7028

Citation: Kuzu Yildirim, S. \& Aricigil Cilan, C. Measuring digital divide in e-commerce by log-linear models and non-parametric tests: an application of Turkey. Journal of Transportation and Logistics, 5(2), 93-104. https://doi.org/10.26650/JTL.2020.0018 


\section{Introduction}

In the digitalizing world, the importance of e-commerce activities is increasing every passing year. As a concept, electronic commerce: according to the World Trade Organization (WTO), is the production, advertising, sale and distribution of goods and services via telecommunications networks. According to the Organisation for Economic Co-operation and Development (OECD), it refers generally to the carrying out of commercial activities by individuals and organizations based upon the transmission of digitized data, including text, sound, and visual images. According to the United Nations Centre for Trade Facilitation and Electronic Business (UN/CEFACT), is defined as sharing of unstructured or structured business information by any electronic means (such as electronic mail or messaging, electronic bulletin boards, World Wide Web technology, smart cards, electronic funds transfers, and electronic data interchange) among suppliers, customers, governmental bodies and other partners in order to conduct transactions in business, administrative and consumer activities. Canpolat (2001) defines e-commerce as a process among consumers, businesses, and public institutions, based upon the processing, transmission, and storage of digital information in the form of text, sound, and visual images in an electronic environment (internet or intranet), for the activities of getting informed and doing research, making a commitment, delivering goods and services to the customer, making payment, performing after-sales maintenance and support services.

As in the world, in Turkey, electronic commerce is growing and becoming more and more popular. Among the reasons for this growth are widespread and affordable internet access, increasing young population, the rise in digital literacy, and the proliferation of smartphone use day by day. When examined from the viewpoint of consumer perceptions, the most important value proposition of e-commerce for Turkish consumers is its price advantage. In advanced e-commerce markets, the perception of convenience stands out more prominently (Turkish Industry \& Business Association, TÜSİAD-T/2017).

The Internet is a channel that enables people to acquire new hobbies and create innovations, facilitates continuing education, encourages personal growth and allows new relationships to be established (Cohendet, 2003). Despite the fact that the primary step in being able to engage in e-commerce is internet access, there are still regions in the world that cannot get access to the internet. Therefore, this situation makes e-commerce activity impossible. This has led to the concept of "Digital Divide", which is known as the gap between individuals, households, business, and geographic areas with regard both to their opportunities to access information and communication technologies (ICTs) and to their use of the internet. This concept, first introduced in the late 1990s, has become an attractive subject for researchers.

\section{The Digital Divide and Its Causes}

The OECD (2001) defined the term "Digital Divide" as the gap between individuals, households, businesses, and geographic areas with regard to both their opportunities to access Information and Communication Technologies (ICT) and to their use of the internet. Dragulanescu (2002) defined it as the gap between those who can afford to purchase 
the computer hardware and software necessary to participate in the global information network, and those that cannot. Hargittai (2003) defined it as the gap between those who have access to digital technologies and those who do not. Dijk (2006) defined it as the gap between those who have access to computers and the internet and those who do not. It is thought that no further deepening of the digital divide and preventing digital poverty will affect the world welfare positively. For reduction of the digital divide and digital poverty, the work carried out at a global level needs to be continued with determination and greater participation (Kalayc1, 2013).

While the number of studies analyzing the digital divide has increased rapidly in recent years, Hoffman and Novak's (1998) study, as an example of pioneering works, assessed whether there was a difference between Whites and African Americans in the United States with respect to computer access and internet use, by examining the income and education levels of the races, and they observed that there was a serious digital divide between these two groups. Ono and Zavodny (2007) examined the microdata of the United States, Sweden, Japan, South Korea and Singapore to determine whether gender, age, education, and income factors created digital inequality ${ }^{1}$. They found that in the United States and Sweden, gender did not have an impact on digital inequality. However, in the other three Asian countries, this inequality was quite profound. Brandtzæg et al. (2011) grouped internet user types as "Non-Users", "Sporadic Users", "Instrumental Users", "Entertainment Users" and "Advanced Users", and he argued that $60 \%$ of users in five European countries consisted of "Non-Users" and "Sporadic Users" and the digital divide in European countries was quite deep. Friemel (2014), when measuring the digital divide between age groups, argued that in parallel with the literature, there was a divide between young people and seniors. In addition, the rate of Internet usage among seniors was also quite different. According to this research, he found that only a quarter of the seniors over 65 got internet access, and as the age increased, this ratio decreased, in other words, the gap widened.

\section{Measurement of the digital divide and the domestic digital divide}

There are two dimensions of the digital divide analysis. These are divided into; measuring the gap between countries (the international digital divide) and measuring the gap between groups within the country (the domestic digital divide) (Cuervo \& Menendez, 2006). The international digital divide is largely the consequence of the social and economic imbalance that exists between developed and developing countries. Countries with lower income and lower educational attainment tend to show lower rates of ICT (Information and Communication Technologies) access and use when compared to countries with higher income and better education (Chinn \& Fairlie, 2007). The Domestic Digital Divide, shows whether there is a division among factors such as gender, age, educational attainment, and income level within the same society (Cuervo \& Menendez, 2006). Keniston (2003) discussed the digital divide in three dimensions as the result of his analytical reviews. The first of these exists within every nation, industrialized or developing, between individuals who are rich, educated, and powerful, and those who are not, the second one is linguistic

1 They considered the digital divide concept as the inequality in information access. 
and cultural (stated as a relatively less noted situation), and the third one is the divide between the rich and poor nations. Kennedy (2003) argued that there was a digital divide between women and men within the same nation and found that women spent less time on the internet due to their domestic responsibilities. Kılıç (2011) stated that in Turkey, in addition to the disparities between low-income and high-income families, significant divides were also observed between regions and educational levels and consequently this caused serious gaps between regions within the country as well. Tsetsi \& Rains (2017) measured the digital divide over smartphone dependence and argued that in the United States, smartphone dependence was correlated with race, gender, age, education. and income level and that there was a gap between the group categories.

\section{Research}

In the present study, the overall profile of those engaged in e-commerce in Turkey was identified first. Then, this profile was examined in terms of what factors of engagement in e-commerce caused the digital divide and which factors were ineffective in the digital divide. The variables used in the research, are given in Table 1.

Table 1. Research variables

\begin{tabular}{|c|c|c|}
\hline Variable & Scale & Category Number \\
\hline Engagement in e-commerce & Nominal & Yes - No \\
\hline Gender & Nominal & Male - Female \\
\hline Age & Ordinal & {$[16-25],[26-35],[36-45],[46-55],[56-65],[66-74]$} \\
\hline Education & Ordinal & $\begin{array}{l}\text { Literate but did not finish any school, Primary School, } \\
\text { Secondary School, High School, Two-year vocational } \\
\text { college, Four-year license, Postgraduate, Doctoral } \\
\text { graduates }\end{array}$ \\
\hline
\end{tabular}

Most of the research variables are categorical. Therefore, the "age" variable, which takes place in the original questionnaire numerically, was examined by dividing into categories, within the scope of the study.

\subsection{Purpose and Scope of Research}

TURKSTAT regularly conducts "Information and Communication Technology (ICT) Usage Survey on Households and Individuals" every year since 2003. In this study, the data of the Information and Communication Technology (ICT) Usage Survey on Households and Individuals from 2016, which was most recently published by TURKSTAT, was used and an analysis was carried out. The purpose of the research was to determine whether there was a digital divide originating from e-commerce. To this end, 14,236 people, in the age range of 16-74, who answered the question of whether or not to engage in e-commerce, were included in the survey.

\subsection{Research Methods}

In field surveys conducted in the Social Sciences, categorical data analysis occupies a large volume. These are frequently used in the analysis of nominal variables, ordinal variables, and discrete variables with a limited number of categories. In research performed utilizing 
categorical data, creating contingency tables has great importance. These tables might be two-way, small-sized, or can also be arranged in larger dimensions and ways. In such cases, frequently used categorical data analysis methods such as Pearson's Chi-Square Test remain insufficient. In three or more dimensional tables, advanced contingency methods are used to determine relationship structures better. Examples of these methods are Log-Linear Models, Correspondence Analysis, and Latent Class Analysis.

\section{Non-Parametric Tests}

Non-parametric tests have an important and extensive place, especially in the analysis of nominal and ordinal scale variables, which are not based on any assumptions about the population distributions and are frequently used in social sciences. One of the most well-known non-parametric statistical techniques is the Pearson Chi-Square $\left(\chi^{2}\right)$ test showing Chi-square $\left(\chi^{2}\right)$ distribution developed by Karl Pearson in 1900. In this test, which examines the independence between two nominal categorical variables, independence is tested in the null hypothesis. Another test that is used to investigate the independence of the categorical variables included in the contingency tables and which is again ChiSquared $\left(\chi^{2}\right)$ is the Likelihood Ratio Chi-Square (G2) test. It is claimed that the $G 2$ statistic is a more favorable test statistic than the $\mathrm{X}^{2}$ statistic, in larger dimension contingency tables (Çilan, 2009).

$$
G^{2}=2 \sum n_{i j k} \log \left(\frac{n_{i j k}}{\hat{\mu}_{i j k}}\right), \quad X^{2}=\sum \frac{\left(n_{i j k}-\hat{\mu}_{i j k}\right)^{2}}{\hat{\mu}_{i j k}}
$$

Examples of independence tests used in Nominal-Ordinal tables include Mann-Whitney/ Wilcoxon and Kolmogorov Smirnov tests, and examples of independence tests used in Ordinal-Ordinal tables include the Jonckheere-Terpstra, Linear Trend Alternative to Independence, and Cochran-Armitage trend tests. These tests are used only for the examination of the two-way relationship. For this reason, in addition to the above tests, it is necessary to examine the multi-way contingency tables as well. In particular, if there is a control variable that is thought to influence the relationship between the two variables, it must be included in the model. Thus, it can be possible to investigate whether the categories of the control variable affect the relationship between the two categorical variables. The Cochran-Mantel-Haenszel test is one of the important tests showing these associations. Log-Linear Models, in which relationships with three-way and more are detected and in which interactions between variables are included in the model, are also used in this research.

\section{Log-Linear Models}

Log-Linear Models are mainly used to specify the associations and interactions between categorical data showing Poisson distribution (Agresti, 1996, p.145). In the literature, these models are generally divided into four groups. These are,

Independence Models; 


$$
\ln \mu_{i j k}=\lambda+\lambda_{i}^{A}+\lambda_{j}^{B}+\lambda_{k}^{C}
$$

It is estimated when the variables A, B, and C are independent of each other, in other words, when there are no binary and triple interactions.

Conditional Independence Models;

$$
\ln \mu_{i j k}=\lambda+\lambda_{i}^{A}+\lambda_{j}^{B}+\lambda_{k}^{C}+\lambda_{i j}^{A B}+\lambda_{i k}^{A C}
$$

It is used when one of the variables is dependent on the other two variables and when these two variables are inter-independent. Equation 3, as an example, is based on the assumption that variables $\mathrm{B}$ and $\mathrm{C}$ are inter-independent but related to variable $\mathrm{A}$.

Homogeneous Association Models;

$$
\ln \mu_{i j k}=\lambda+\lambda_{i}^{A}+\lambda_{j}^{B}+\lambda_{k}^{C}+\lambda_{i j}^{A B}+\lambda_{i k}^{A C}+\lambda_{j k}^{B C}
$$

These are the models which contains both the respective effects of the three variables and all their binary interactions with each other.

Saturated Models;

$$
\ln \mu_{i j k}=\lambda+\lambda_{i}^{A}+\lambda_{j}^{B}+\lambda_{k}^{C}+\lambda_{i j}^{A B}+\lambda_{i k}^{A C}+\lambda_{j k}^{B C}+\lambda_{i j k}^{A B C}
$$

It is estimated in the case when all one-way, two-way and three-way associations that can be formed using variables are meaningful.

\subsection{Analysis Results}

According to the data obtained from TURKSTAT's Information and Communication Technology (ICT) Usage Survey on Households and Individuals 2016, there were 14,236 people from the age group 16-74 who responded to the question of whether or not engaging in e-commerce. Accordingly, in Turkey, the proportion of those who at least once over the past year engaged in e-commerce is $28.5 \%$. $54.2 \%$ of those engaging in e-commerce are male and $45.8 \%$ female. In addition, those between the ages [16-25] comprise $27.2 \%$ of the e-commerce users, those between the ages [26-35] comprise $28.7 \%$, those between the ages [36-45] comprise $24.2 \%$, those between the ages [46-55] comprise $13.2 \%$, those between the ages [56-65] comprise 5.6\%, and those between the ages [66-74] comprise $1.2 \%$. According to the education levels, $22.8 \%$ are primary school + literate uneducated individuals, $52.5 \%$ are secondary school + high school graduates, $22.3 \%$ are 2-year + 4-year faculty graduates and $2.5 \%$ are postgraduate and doctoral graduates.

Whether or not the gender affects engagement in e-commerce was first investigated by Pearson Chi-Square and Likelihood Ratio tests, and no relation was found, according to the results in Table 2. Accordingly, gender does not affect engagement in e-commerce. 
Table 2. Results of Pearson Chi-Square \& Likelihood Ratio Tests

\begin{tabular}{|l|c|c|c|c|}
\hline & \multicolumn{2}{|c|}{ Pearson Chi-Square } & \multicolumn{2}{c|}{ Likelihood Ratio } \\
\hline & Value & Asym. Sig & Value & Asym. Sig \\
\hline e-commerce \& gender & 0.001 & 0.971 & 0.001 & 0.971 \\
\hline
\end{tabular}

The Cochran-Mantel-Haenszel Test was applied to examine whether there was a relationship between e-commerce and gender, also at different education levels in addition to the dual interaction. When the "Education level" was considered as the control variable here, the results are given in Table 3. Accordingly, it was determined, with $\mathrm{p}=0.465$ and $p=0.478$ probabilities, that engagement-nonengagement in e-commerce was not related to gender; that is, similar results were obtained with Chi-square tests.

Table 3. Results of Cochran-Mantel-Haenszel Test

\begin{tabular}{|l|c|c|}
\hline & Chi-Squared & Asymp. Sig. \\
\hline Cochran's & 0.533 & 0.465 \\
\hline Mantel-Haenszel & 0.504 & 0.478 \\
\hline
\end{tabular}

Whether or not the engagement in e-commerce is related to the ordinal variables "age" and "education" were examined via Mann-Whitney U \& Wilcoxon W Tests. According to the results in Table 4, the status of engaging in e-commerce is related to the variables "education" and "age".

Table 4. Results of Mann-Whitney U \& Wilcoxon W Tests

\begin{tabular}{|l|c|c|c|c|}
\hline & Mann-Whitney U & Wilcoxon W & Z & Asymp. Sig. \\
\hline e-commerce \& age & 18197209.500 & 26416694.500 & -11.382 & 0.000 \\
\hline e-commerce \& education & 11514846.000 & 63356499.000 & -45.184 & 0.000 \\
\hline
\end{tabular}

According to the results of the Jonckheere-Terpstra test, which analyzes the relation between Ordinal-Ordinal variables, there is a relation between the "age" and "education" variables (probability $\mathrm{p}=0.000$ ). Finally, the relationship between gender and education were also examined and found to be related by a probability of $p=0.000$.

The odds ratios between the education and age variables, which were found to be relevant, were calculated. The odds ratio between the education level variable, which was rearranged as "pre-high school" and "post-high school", and the e-commerce engagement-nonengagement variable is 5.54. In other words, those with high school and above education levels are approximately 5.54 times more likely to engage in e-commerce. The odds ratio between the age variable, which was rearranged as "under the age of 45 " and "over the age of 45 ", and the e-commerce engagement-nonengagement variable is 2.32 . In other words, the probability of engaging in e-commerce for those under the age of 45 is approximately 2.32 times more.

The relationships found between e-commerce, gender, and education variables are summarized in Figure 1. According to this, it was observed that gender does not create any discrimination in the case of engaging in e-commerce, however, those who engage in e-commerce and those who do not, differ according to their education levels. In addition, the level of education as well was found to be dependent on gender. 


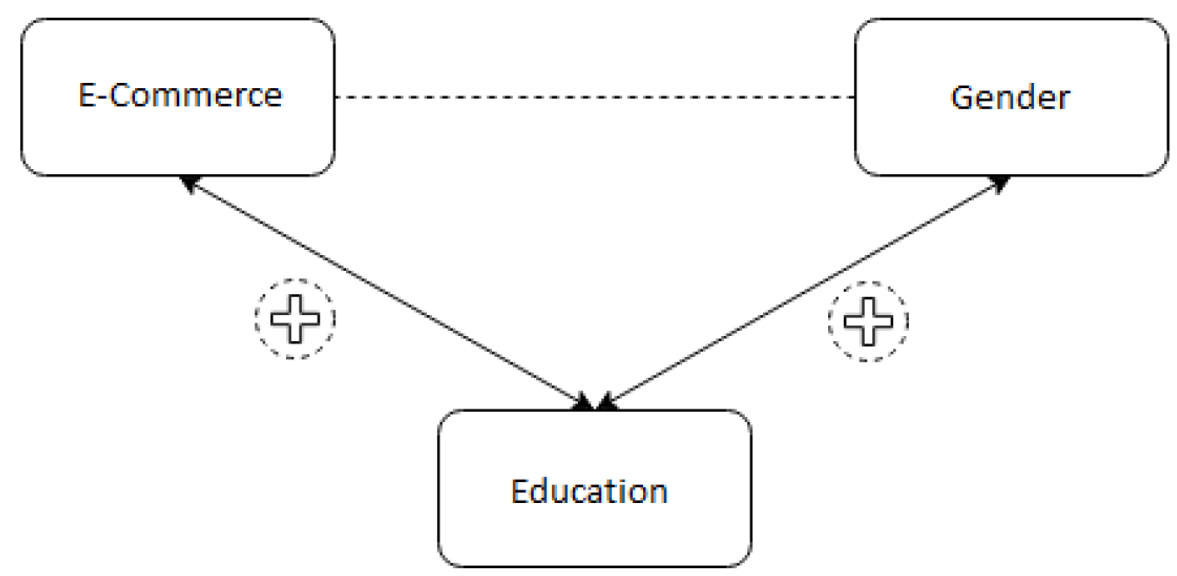

Figure 1. E-Commerce, Gender, Education relationship

All the Log-linear models that can be set up in the light of the above information and in the direction of the models proposed by Agresti are given in Table 5.

Table 5. Three-way Log-Linear Models between E-Commerce, Gender, Education

\begin{tabular}{|c|c|c|c|c|c|}
\hline \multirow[b]{2}{*}{ Model } & \multicolumn{5}{|c|}{ Goodness-of-Fit } \\
\hline & $\begin{array}{c}\text { Likelihood } \\
\text { Ratio }\end{array}$ & Sig. & $\begin{array}{c}\text { Pearson } \\
\text { Chi- } \\
\text { Square }\end{array}$ & Sig. & S.D. \\
\hline $\ln \mu_{i j k}=\lambda+\lambda_{i}^{A}+\lambda_{j}^{B}+\lambda_{k}^{C}$ & 2194.31 & 0.000 & 2191.58 & 0.000 & 10 \\
\hline $\ln \mu_{i j k}=\lambda+\lambda_{i}^{A}+\lambda_{j}^{B}+\lambda_{k}^{C}+\lambda_{i j}^{A B}$ & 2194.31 & 0.000 & 2191.48 & 0.000 & 9 \\
\hline $\ln \mu_{i j k}=\lambda+\lambda_{i}^{A}+\lambda_{j}^{B}+\lambda_{k}^{C}+\lambda_{i k}^{A C}$ & 13.939 & 0.052 & 13.835 & 0.054 & 7 \\
\hline $\ln \mu_{i j k}=\lambda+\lambda_{i}^{A}+\lambda_{j}^{B}+\lambda_{k}^{C}+\lambda_{j k}^{B C}$ & 2182.85 & 0.000 & 2170.30 & 0.000 & 7 \\
\hline $\ln \mu_{i j k}=\lambda+\lambda_{i}^{A}+\lambda_{j}^{B}+\lambda_{k}^{C}+\lambda_{i k}^{A C}+\lambda_{j k}^{B C}$ & 2.475 & 0.649 & 2.478 & 0.649 & 4 \\
\hline $\ln \mu_{i j k}=\lambda+\lambda_{i}^{A}+\lambda_{j}^{B}+\lambda_{k}^{C}+\lambda_{i j}^{A B}+\lambda_{j k}^{B C}$ & 2182.85 & 0.000 & 2170.26 & 0.000 & 6 \\
\hline $\ln \mu_{i j k}=\lambda+\lambda_{i}^{A}+\lambda_{j}^{B}+\lambda_{k}^{C}+\lambda_{i j}^{A B}+\lambda_{i k}^{A C}$ & 13.938 & 0.030 & 13.835 & 0.032 & 6 \\
\hline $\ln \mu_{i j k}=\lambda+\lambda_{i}^{A}+\lambda_{j}^{B}+\lambda_{k}^{C}+\lambda_{i j}^{A B}+\lambda_{i k}^{A C}+\lambda_{j k}^{B C}$ & 1.942 & 0.585 & 1.945 & 0.584 & 3 \\
\hline $\ln \mu_{i j k}=\lambda+\lambda_{i}^{A}+\lambda_{j}^{B}+\lambda_{k}^{C}+\lambda_{i j}^{A B}+\lambda_{i k}^{A C}+\lambda_{j k}^{B C}+\lambda_{i j k}^{A B C}$ & 0.000 & 0.000 & 0.000 & 0.000 & 0 \\
\hline Table (Agresti, 2002, p.320) $\quad \mathrm{A}=\mathrm{E}-\mathrm{C}$ - ommerce $\mathrm{B}=$ Gender $\mathrm{C}=$ Education & & & & & \\
\hline
\end{tabular}

When Table 5 is examined, it shows that only two models are significant. Among these models, the model with high goodness-of-fit is the model that at the same time comprises the associations (dual interactions) which are also found in non-parametric test results. In this case, the selected log-linear model is the conditional independence model which is indicated as follows:

$$
\ln \mu_{i j k}=\lambda+\lambda_{i}^{A}+\lambda_{j}^{B}+\lambda_{k}^{C}+\lambda_{i k}^{A C}+\lambda_{j k}^{B C}
$$


According to the model shown by Equation 6, the dual interactions of E-Commerce $\&$ Education and Gender \& Education are also included in the model. The parameter estimates pertaining to this model are given in Table 6.

Table 6. Parameter Estimates

\begin{tabular}{|l|c|c|c|c|}
\hline Parameters & $\begin{array}{c}\text { Estimated } \\
\text { Value }\end{array}$ & $\begin{array}{c}\text { Standard } \\
\text { Error }\end{array}$ & $\begin{array}{c}\mathbf{Z} \\
\text { Value }\end{array}$ & Sig. \\
\hline Invariant & 3.634 & 0.121 & 29.997 & 0.000 \\
\hline$[$ E-Commerce $=1.00]$ & 0.942 & 0.118 & 7.952 & 0.000 \\
\hline$[$ E- Commerce $=2.00]$ & 0 &. &. &. \\
\hline$[$ Gender $=1.00]$ & 0.479 & 0.110 & 4.376 & 0.000 \\
\hline$[$ Gender $=2.00]$ & 0 &. &. &. \\
\hline$[$ Education $=1.00]$ & 3.616 & 0.124 & 29.184 & 0.000 \\
\hline$[$ Education $=2.00]$ & 4.222 & 0.123 & 34.461 & 0.000 \\
\hline$[$ Education $=3.00]$ & 2.850 & 0.125 & 22.714 & 0.000 \\
\hline$[$ Education $=4.00]$ & 0 &. &. &. \\
\hline$[$ E-Comm $=1.00] *[$ Educat $=1.00]$ & -3.377 & 0.135 & -25.029 & 0.000 \\
\hline$[$ E- Comm $=1.00] *[$ Educat $=2.00]$ & -2.096 & 0.122 & -17.247 & 0.000 \\
\hline$[$ E- Comm $=1.00] *[$ Educat $=3.00]$ & -0.738 & 0.124 & -5.963 & 0.000 \\
\hline$[$ E- Comm $=1.00] *[$ Educat $=4.00]$ & 0 &. &. &. \\
\hline$[$ E- Comm $=2.00] *[$ Educat $=1.00]$ & 0 &. &. &. \\
\hline$[$ E- Comm $=2.00] *[$ Educat $=2.00]$ & 0 &. &. &. \\
\hline$[$ E- Comm $=2.00] *[$ Educat $=3.00]$ & 0 &. &. &. \\
\hline$[$ E- Comm $=2.00] *[$ Educat $=4.00]$ & 0 &. &. &. \\
\hline$[$ Gender $=1.00] *[$ Educat $=1.00]$ & -0.370 & 0.115 & -3.221 & 0.001 \\
\hline$[$ Gender $=1.00] *[$ Educat $=2.00]$ & -0.297 & 0.112 & -2.655 & 0.008 \\
\hline$[$ Gender $=1.00] *[$ Educat $=3.00]$ & -0.317 & 0.115 & -2.751 & 0.006 \\
\hline$[$ Gender $=1.00] *[$ Educat $=4.00]$ & 0 &. &. &. \\
\hline$[$ Gender $=2.00] *[$ Educat $=1.00]$ & 0 &. &. &. \\
\hline$[$ Gender $=2.00] *[$ Educat $=2.00]$ & 0 &. &. &. \\
\hline$[$ Gender $=2.00] *[$ Educat $=3.00]$ & 0 &. &. &. \\
\hline$[$ Gender $=2.00] *[$ Educat $=4.00]$ & 0 &. &. &. \\
\hline & & &. &. \\
\hline
\end{tabular}

When the $\mathrm{Z}$ values of one-way relation terms are examined, it shows that the most important factor determining the frequencies in the contingency table is "education". It also shows that dependence exists between the variables of e-commerce \& education and education $\&$ gender. It is understood that engagement in e-commerce is dependent on education and this dependency is mostly in groups with education categories 1,2, 3. It is not possible to mention any relationship between education and the status of not engaging in e-commerce. Furthermore, it is seen that education is dependent on gender and this dependence is mostly on men and in groups with education categories 1, 2, 3 . However, looking at the $\mathrm{Z}$ values, this dependence is not as high as between e-commerce and education.

In addition, the Poisson distribution of this selected model is shown in Figure 2, and the observed and expected frequencies and percentages are given in Table 7. 


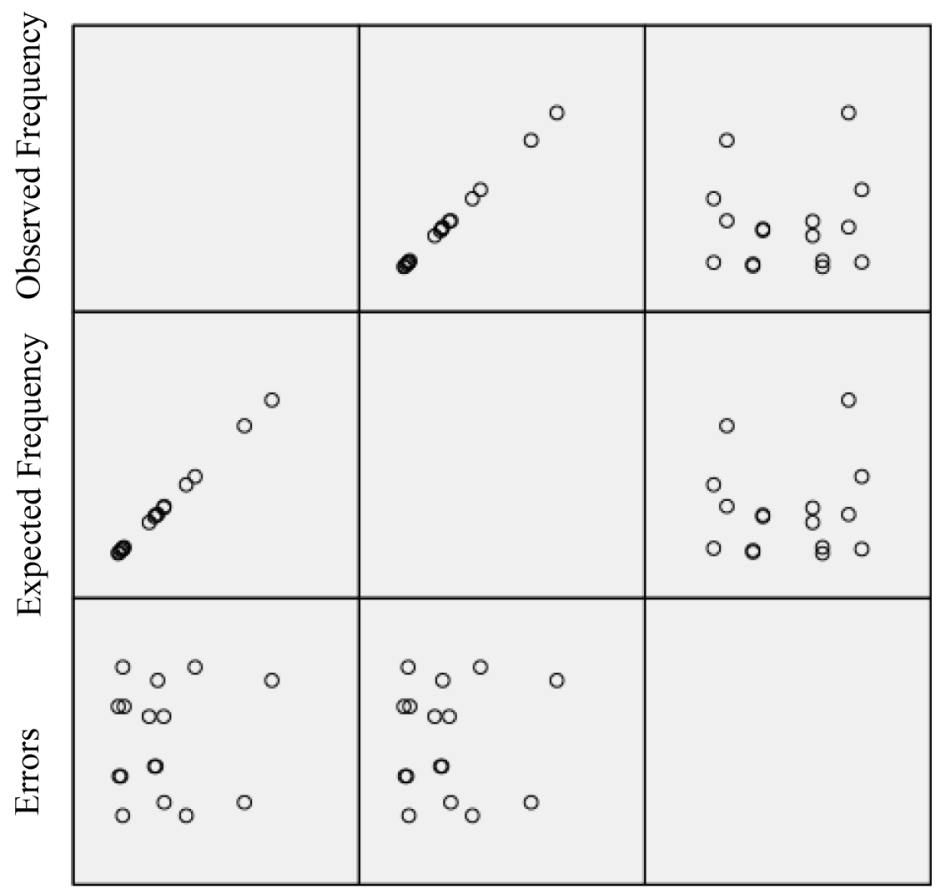

Observed Frequency Expected Frequency Errors

Figure 2. Poisson Model

Table 7. Observed and Expected Frequencies

\begin{tabular}{|c|c|c|c|c|c|c|}
\hline \multirow{2}{*}{ Gender } & \multirow{2}{*}{ Education } & \multirow{2}{*}{ E-Commerce } & \multicolumn{2}{|c|}{ Observed } & \multicolumn{2}{|c|}{ Expected (E) } \\
\hline & & & Frequency & $\%$ & Frequency & $\%$ \\
\hline \multirow{8}{*}{ Male } & \multirow{2}{*}{ Primary School } & Yes & 129 & $0.9 \%$ & 137.589 & $1.0 \%$ \\
\hline & & No & 1579 & $11.1 \%$ & 1570.411 & $11.0 \%$ \\
\hline & \multirow{2}{*}{ Secondary School } & Yes & 960 & $6.7 \%$ & 976.778 & $6.9 \%$ \\
\hline & & No & 3114 & $21.9 \%$ & 3097.222 & $21.8 \%$ \\
\hline & \multirow{2}{*}{ High School } & Yes & 950 & $6.7 \%$ & 944.790 & $6.6 \%$ \\
\hline & & No & 765 & $5.4 \%$ & 770.210 & $5.4 \%$ \\
\hline & \multirow{2}{*}{ Two-Year College } & Yes & 159 & $1.1 \%$ & 156.861 & $1.1 \%$ \\
\hline & & No & 59 & $0.4 \%$ & 61.139 & $0.4 \%$ \\
\hline \multirow{8}{*}{ Female } & \multirow{2}{*}{ Primary School } & Yes & 132 & $0.9 \%$ & 123.411 & $0.9 \%$ \\
\hline & & No & 1400 & $9.8 \%$ & 1408.589 & $9.9 \%$ \\
\hline & \multirow{2}{*}{ Secondary School } & Yes & 831 & $5.8 \%$ & 814.222 & $5.7 \%$ \\
\hline & & No & 2565 & $18.0 \%$ & 2581.778 & $18.1 \%$ \\
\hline & \multirow{2}{*}{ High School } & Yes & 798 & $5.6 \%$ & 803.210 & $5.6 \%$ \\
\hline & & No & 660 & $4.6 \%$ & 654.790 & $4.6 \%$ \\
\hline & \multirow{2}{*}{ Two-Year College } & Yes & 95 & $0.7 \%$ & 97.139 & $0.7 \%$ \\
\hline & & No & 40 & $0.3 \%$ & 37.861 & $0.3 \%$ \\
\hline
\end{tabular}

Log-Linear Models were re-established by taking "Age" variable instead of "Education" variable, but no meaningful model could be found according to the results in Table 8 . 
Table 8. Three-way Log-Linear Models between E-Commerce, Gender, Age

\begin{tabular}{|c|c|c|c|c|c|}
\hline \multirow[b]{2}{*}{ Model } & \multicolumn{5}{|c|}{ Goodness-of-Fit } \\
\hline & $\begin{array}{c}\text { Likelihood } \\
\text { Ratio }\end{array}$ & Sig. & $\begin{array}{c}\text { Pearson } \\
\text { Chi- } \\
\text { Square }\end{array}$ & Sig. & S.D. \\
\hline $\ln \mu_{i j k}=\lambda+\lambda_{i}^{A}+\lambda_{j}^{B}+\lambda_{k}^{C}$ & 546.072 & 0.000 & 518.561 & 0.000 & 16 \\
\hline $\ln \mu_{i j k}=\lambda+\lambda_{i}^{A}+\lambda_{j}^{B}+\lambda_{k}^{C}+\lambda_{i j}^{A B}$ & 546.071 & 0.000 & 518.678 & 0.000 & 15 \\
\hline $\ln \mu_{i j k}=\lambda+\lambda_{i}^{A}+\lambda_{j}^{B}+\lambda_{k}^{C}+\lambda_{i k}^{A C}$ & 178.084 & 0.000 & 174.497 & 0.000 & 11 \\
\hline $\ln \mu_{i j k}=\lambda+\lambda_{i}^{A}+\lambda_{j}^{B}+\lambda_{k}^{C}+\lambda_{j k}^{B C}$ & 386.159 & 0.000 & 365.625 & 0.000 & 11 \\
\hline $\ln \mu_{i j k}=\lambda+\lambda_{i}^{A}+\lambda_{j}^{B}+\lambda_{k}^{C}+\lambda_{i k}^{A C}+\lambda_{j k}^{B C}$ & 18.171 & 0.006 & 17.851 & 0.007 & 6 \\
\hline $\ln \mu_{i j k}=\lambda+\lambda_{i}^{A}+\lambda_{j}^{B}+\lambda_{k}^{C}+\lambda_{i j}^{A B}+\lambda_{j k}^{B C}$ & 386.158 & 0.000 & 365.629 & 0.000 & 10 \\
\hline $\ln \mu_{i j k}=\lambda+\lambda_{i}^{A}+\lambda_{j}^{B}+\lambda_{k}^{C}+\lambda_{i j}^{A B}+\lambda_{i k}^{A C}$ & 178.082 & 0.000 & 174.498 & 0.000 & 10 \\
\hline $\ln \mu_{i j k}=\lambda+\lambda_{i}^{A}+\lambda_{j}^{B}+\lambda_{k}^{C}+\lambda_{i j}^{A B}+\lambda_{i k}^{A C}+\lambda_{j k}^{B C}$ & 15.227 & 0.009 & 15.022 & 0.010 & 5 \\
\hline $\ln \mu_{i j k}=\lambda+\lambda_{i}^{A}+\lambda_{j}^{B}+\lambda_{k}^{C}+\lambda_{i j}^{A B}+\lambda_{i k}^{A C}+\lambda_{j k}^{B C}+\lambda_{i j k}^{A B C}$ & 0.000 & 0.000 & 0.000 & 0.000 & 6 \\
\hline
\end{tabular}

\section{Conclusion}

In the digitalizing world, the internet and conveniences that it provides are drawing greater interest, day by day. Nevertheless, there are still regions in the world that do not have internet penetration, which results in a digital divide among individuals. In general, the digital divide is measured in two ways. The first is the difference between countries/regions in accessing the internet and computer technologies, and the second is the difference between individuals' access to the internet and computer technologies within the same country/region. In this study, according to the individuals' demographic structures in Turkey, the effect on the status of e-commerce engagement was investigated. In addition, it examined whether there was a digital divide between individuals who engaged in e-commerce and those who did not. Consequently, unlike other developing countries, in Turkey, it was determined that the status of engaging or not engaging in e-commerce did not vary by sex, that is, gender did not cause a digital divide. However, the status of engaging in e-commerce presented a significant difference according to education levels. Parallel to the literature, also in Turkey, as educational levels increase the number of people who use e-commerce applications rise. According to the analysis carried out via MicroData Set, 2016 of TURKSTAT's Information Technologies Usage Survey on Households, the probability of engaging in e-commerce for those with high school and above education levels is approximately 5.54 times higher. It is argued that the digital divide exists between individuals in Turkey, according to their educational levels. It was suggested to increase digital literacy first in order to see a a decrease in the 
digital divide. The rise in digital literacy will cause a proliferation of internet usage and an increase in transactions over the Internet. Besides, individuals should benefit more from the price advantage and convenience provided by e-commerce.

\section{References}

Agresti, A., (1996). An Introduction to Categorical Data Analysis, John Wiley \& Sons,Inc, USA.

Agresti, A., (2002). Categorical data analysis, second edition, John Wiley \& Sons, Inc, USA.

Arıcıgil Çilan, Ç., (2009). Sosyal bilimlerde kategorik verilerle ilişki analizi, Pegem Akademi, Ankara.

Canpolat, Önder, (2001). E-Ticaret ve Türkiye'deki gelişmeler, T.C. Sanayi ve Ticaret Bakanlığı Hukuk Müşavirliği.

Kalayc1, C. (2013). Dijital bölünme, dijital yoksulluk ve uluslararası ticaret. Atatürk Üniversitesi İktisadi ve İdari Bilimler Dergisi, 27(3), 145-162.

Kılıç, Ç. (2011). Küreselleşen dünyada dijital bölünme sorunu. Erzincan Eğitim Fakültesi Dergisi, 13(1), 81-91

Donna L. Hoffman, Thomas P. Novak, (1998). Bridging the Racial Divide on the Internet. Science, 280(5362), 390-391.

Eric Tsetsi \& Stephen A. Rains, (2017). Smartphone internet access and use: Extending the digital divide and usage gap. Mobile Media \& Communication, 5(3), 239-255

Hargittai, E. (2003). The Digital Divide and What to Do about it?, New Economy Hand Book, Chapter 35, Elsevier Science USA.

Keniston, K., \& Kumar, D. (2003). The four digital divides, In Press at Sage Publishers

Jan A.G.M. van Dijk, (2006). Digital divide research, achievements and shortcomings, Poetics, 34(4-5), 221-235.

Mar1'a Rosal1'a Vicente Cuervo \& Ana Jesu's Lo'pez Mene'ndez (2006). A multivariate framework for the analysis of the digital divide: evidence for the european union-15. Information \& Management, 43(6), 756-766.

Menzie D. Chinn Robert W. Fairlie, (2007). The determinants of the global digital divide: a cross-country analysis of computer and internet penetration. Oxford Economic Papers, 59(1) 16-44.

Dragulanescu, N. G. (2002). Social impact of the "Digital Divide" in a Central-Eastern European country. The International Information \& Library Review, 34(2), 139-151.

OECD, (2007) Understanding the Digital Divide, https://www.oecd.org/sti/1888451.pdf, Erişim Tarihi: 11.07.2017, 1-32.

Ono, H., \& Zavodny, M. (2007). Digital inequality: A five country comparison using microdata. Social Science Research, 36(3), 1135-1155.

Brandtzæg, P. B., Heim, J., \& Karahasanović, A. (2011). Understanding the new digital divide-A typology of Internet users in Europe. International journal of human-computer studies, 69(3), 123-138.

Cohendet, P. (2003). The digital divide in the European enlarged economic scenario: an assessment of the socio-economic effects. Strasbourg: University Louis Pasteur.

Friemel, T. N. (2014) The digital divide has grown old: Determinants of a digital divide among seniors. New Media \& Society, 18(2), 313-331.

Kennedy, T., Wellman, B., \& Klement, K. (2003). Gendering the digital divide. IT \& society, 1(5), 72-96. 